\title{
COMBINED NONPARAMETRIC CHI-SQUARED AND BINOMIAL STATISTICAL TEST ON TRUCK TRAFFIC VOLUME CHANGES IN CANADIAN PROVINCIAL HIGHWAY NETWORK
}

\author{
Hyuk-Jae $\mathrm{ROH}^{1^{*}}$, Satish SHARMA ${ }^{2}$ \\ ${ }^{1}$ Dept of Roadways and Transportation, City of Regina, Canada \\ ${ }^{2}$ Dept of Environmental Systems Engineering, University of Regina, Canada
}

Received 20 March 2016; revised 17 November 2016; accepted 18 January 2017

\begin{abstract}
This paper examines the effect of weather conditions on truck type distribution using combined nonparametric chi-squared and binomial probability statistical tests. Influence of the winter conditions on truck type distribution is investigated in this paper by classifying trucks into single-unit trucks, single-trailer, and multi-trailer units. The investigation is based on 5 years Weigh-In-Motion (WIM) traffic data collected from Alberta provincial highway network in Canada. The WIM data is collected from six WIM sites located on Highway 2, Highway 2A, Highway 3, Highway 16 and Highway 44. The objective of this study is to investigate the association of three truck type distribution with month and season depending on weather conditions by means of nonparametric statistical test. The statistical results indicate that the variation of truck type distribution is influenced by type of highway facility, such as regional commuter roads and rural long distance highways. The season of the year (winter and non-winter) may also affect the truck type distribution on some types of roads. Findings of this study can benefit highway agencies in developing programs and policies related to efficient monitoring of truck traffic and maintaining highway network throughout the year.
\end{abstract}

Keywords: truck type distribution, weigh-in-motion, vehicle classification, chi-squared test, binomial test.

\section{Introduction}

Highway traffic volume varies over time and locations on all roadways. The variations of traffic volumes could differ substantially when each vehicle class travelling in the same traffic stream is analysed separately. Severe winter weather condition in Canada is another factor, which causes more variations in traffic streams. Datla and Sharma (2008) analysed the impact of winter weather conditions (cold temperatures and snowfall) on highway total traffic volumes. They concluded that winter weather causes significant variations in traffic volumes, and the magnitude of variation depends on the time of day, day of the week, location, highway type, and severity of the weather. However, their study and other similar studies published in the literature were conducted solely on the basis of total traffic volume data. A few of researches (Roh et al. 2012, 2015, 2016a, 2016b) concluded that total traffic and passenger car volumes are influenced by both the snowfall and the cold temperatures, but the truck volume is not significantly affected by the amount of snowfall or severity of cold tem- peratures. Described in these papers are an extension of the research that was reported by Roh et al. (2012). This paper presents an investigation of the influence of the winter conditions on truck type distributions by classifying trucks into three classes: single-unit trucks, single-trailer, and multi-trailer units. The study findings are based on the five years spanning from 2005 to 2009 truck traffic data collected from six Weigh-In-Motion (WIM) sites located on Highway 2, Highway 2A, Highway 3, Highway 16 and Highway 44 in Alberta (Canada).

The key objective of this study is to investigate the association of three truck type distribution with month and season depending on weather conditions such as snowfall and temperature. Two types of temporal variations of truck type distributions are investigated: (1) month to month variations; (2) season to season variations in which the months of November to March representing severe snowfall and cold conditions are grouped into winter months (namely $5 \mathrm{WMs}$ ). April to October

${ }^{*}$ Corresponding author. E-mail: hyukjae.roh@gmail.com 
are grouped into non-winter months (namely $7 \mathrm{NWMs).}$ December to February are grouped into another winter months (namely $3 \mathrm{WMs}$ ), in order to represent more severe weather condition during winter season than $5 \mathrm{WMs}$. Liu (2006) investigated holiday effects on hourly volume changes with Permanent Traffic Counters (PTCs) data collected continuously for 10 years on highway networks in Alberta (Canada). He compared hourly traffic pattern of typical days with the hourly traffic pattern of holiday and indicated statistical significance of hourly traffic peaking in holiday with the help of combined chi-squared $\left(\chi^{2}\right)$ and binomial tests. Based on the literature, combined nonparametric chi-squared and binomial probability tests of statistical significance are used to analyse the association of winter weather with the variations of truck type volumes under different weather conditions.

\section{Literature review}

The previous studies on highway traffic with regard to weather effects can be divided broadly into three categories. In the first category, Colyar et al. (2003) and Goodwin (2002) studied the effect of weather on highway and traffic conditions. These studies explained the impact of weather events on highway traffic conditions focusing on (1) driver behaviour; (2) roadway safety; (3) roadway mobility. The second category studies report the quantitative association of traffic volumes with weather conditions. Hanbali and Kuemmel (1993) studied the traffic volume reduction on highway traffic due to winter storm conditions and reported that traffic volume is reduced on weekends from 19 to $31 \%$ for light snow and $56 \%$ for heavy snow and on weekday from 7 to $17 \%, 53 \%$ respectively using the data collected at 11 locations during the first three months of 1991 in the United States. Changnon (1996) studied the impact of various precipitation patterns in summer on travel patterns in Chicago. For Lothian region (Scotland) Hassan and Barker (1999) studied the association of traffic with meteorological parameters such as minimum and maximum temperatures, snow and rainfall, snow on ground and sunshine hours. Knapp and Smithson (2000) analysed the average traffic reductions on interstate highways in Iowa State during winter storms. Keay and Simmonds (2005) reported the association of rainfall and other weather variables with traffic volume on urban arterials in Melbourne (Australia). On Inter-State Highway 35 in northern rural Iowa, Maze et al. (2006) reported a strong correlation between the percentage reduction in traffic volume and wind speed and visibility during snowy days. Datla and Sharma (2008) studied the impact of cold and snow on daily and hourly traffic volumes on provincial highways of Alberta (Canada). In the third category, Hanbali and Kuemmel (1993), Maki (1999), Kilpeläinen and Summala (2007) focus on the traveller behaviour (e.g. trip adjustment by trip maker) during adverse weather condi- tions. Several other studies have also reported variations in traffic volume levels and changes in traffic patterns during adverse weather conditions. All of these studies reported reductions in traffic and changes in traffic patterns due to adverse weather conditions. However, none of the past researches investigated the variations of truck traffic volumes during winter weather conditions, and presented comparative analysis in statistical terms of truck traffic distribution between month and season. There is lack of information in literature regarding the impacts of winter weather condition on the variations of truck traffic. Several studies (Roh et al. 2012, 2016a, 2016b) concluded that the truck volume is not significantly affected regardless of the amount of snowfall or severity of cold temperatures through dummy variable regression technique. Described in this paper is an extension of the research presented by Roh et al. (2012) and it aims to investigate the variations of truck type distribution triggered by season and month in mixed highway traffic stream.

\section{The WIM and weather data}

Alberta Transportation is responsible for maintaining highway network in the province of Alberta (Canada). Traffic data by vehicle-by-vehicle configuration including load, and other information were collected for the study period from 2005 to 2009 for supporting programs such as Alberta's Strategic Highway Research Program (SHRP) and Long Term Pavement Performance (LTPP) (Kilburn 2008). The six WIM sites are located on Highway 2, Highway 2A, Highway 3, Highway 16, and Highway 44 as shown in Figure 1. There are two WIM sites at Leduc Vis and Red Deer on Highway 2 and one site for each of the remaining highways. Table 1 shows Annual Average Daily Traffic (AADT) values and the total number of vehicle records summed for all the six WIM sites for 5 years study period from 2005 to 2009. A total number of 154133231 vehicular records were finally used for the purpose of the investigation carried out in this study. It should also be noted that Visual Basic (VB) computer codes were developed to convert the raw data format consisting of 60 variables into 30 variables data format as described in Table 2. Finally, a matrix dimensioned by $154133231 \times 30$ was plugged into classification algorithm called Federal Highway Administration (FHWA) scheme F. The weather data is obtained from Environment Canada's National Climate Data and Information Archive (Canada.ca 2010). Environment Canada collects climate data from nearly 8000 weather stations including many intermittent ones across the country. Figure 1 shows weather stations located nearby the study WIM sites. Each of these weather stations provide detailed weather parameters such as maximum, minimum, and mean temperature $\left[{ }^{\circ} \mathrm{C}\right]$, total rain $[\mathrm{mm}]$, total snow $[\mathrm{cm}]$, total precipitation $[\mathrm{mm}]$ and snow on ground $[\mathrm{cm}]$ on a daily basis. 
Table 1. Summary of vehicle records for WIM sites

\begin{tabular}{|c|c|c|c|}
\hline WIM site & Year & AADT & $\begin{array}{l}\text { Number of vehicle } \\
\text { records }\end{array}$ \\
\hline \multirow{6}{*}{$\begin{array}{l}\text { Red Deer } \\
\text { Highway } 2\end{array}$} & 2005 & 30480 & 11125215 \\
\hline & 2006 & 29780 & 10869702 \\
\hline & 2007 & 33365 & 12178089 \\
\hline & 2008 & 31165 & 11406341 \\
\hline & 2009 & 31509 & 11500838 \\
\hline & \multicolumn{2}{|c|}{ Sub total } & 57080185 \\
\hline \multirow{6}{*}{$\begin{array}{l}\text { Leduc } \\
\text { Highway } 2\end{array}$} & 2005 & 22563 & 8235622 \\
\hline & 2006 & 24170 & 8822202 \\
\hline & 2007 & 25111 & 9165378 \\
\hline & 2008 & 24270 & 8882797 \\
\hline & 2009 & 25426 & 9280645 \\
\hline & \multicolumn{2}{|c|}{ Sub total } & 44386644 \\
\hline \multirow{6}{*}{$\begin{array}{l}\text { Leduc } \\
\text { Highway 2A }\end{array}$} & 2005 & 7195 & 2626346 \\
\hline & 2006 & 7438 & 2714938 \\
\hline & 2007 & 7843 & 2862641 \\
\hline & 2008 & 7761 & 2840488 \\
\hline & 2009 & 7569 & 2762598 \\
\hline & \multicolumn{2}{|c|}{ Sub total } & 13807011 \\
\hline \multirow{6}{*}{$\begin{array}{l}\text { Fort } \\
\text { MacLeod } \\
\text { Highway } 3\end{array}$} & 2005 & 6601 & 2409434 \\
\hline & 2006 & 7369 & 2689743 \\
\hline & 2007 & 7466 & 2725015 \\
\hline & 2008 & 6587 & 2411010 \\
\hline & 2009 & 7124 & 2600201 \\
\hline & \multicolumn{2}{|c|}{ Sub total } & 12835403 \\
\hline \multirow{6}{*}{$\begin{array}{l}\text { Edson } \\
\text { Highway } 16\end{array}$} & 2005 & 7290 & 2660754 \\
\hline & 2006 & 7763 & 2833664 \\
\hline & 2007 & 7481 & 2730397 \\
\hline & 2008 & 7192 & 2632349 \\
\hline & 2009 & 6832 & 2493660 \\
\hline & \multicolumn{2}{|c|}{ Sub total } & 13350824 \\
\hline \multirow{7}{*}{$\begin{array}{l}\text { Villeneuve } \\
\text { Highway } 44\end{array}$} & 2005 & 6614 & 2414263 \\
\hline & 2006 & 7044 & 2571089 \\
\hline & 2007 & 7606 & 2776120 \\
\hline & 2008 & 6729 & 2462839 \\
\hline & 2009 & 6709 & 2448853 \\
\hline & \multicolumn{2}{|c|}{ Sub total } & 12673164 \\
\hline & \multicolumn{2}{|c|}{ Total Records } & 154133231 \\
\hline
\end{tabular}

\section{Vehicle classification}

Classification mechanism of the FHWA 13 category scheme F (Wyman et al. 1985) was adopted for vehicle classification in this study. The classification scheme used information on axle spacing and number as classification measures that were collected for each of vehicle travelling on the WIM site. The layout of WIM site is described in Figure 2. It is consisted of loop sensor for measuring length and piezoelectric sensor for counting axle numbers, capturing collaboratively the configuration patterns of each vehicle passing on the detection area (Kilburn 2008).

The FHWA scheme $\mathrm{F}$ is established using VB computer codes. Vehicle classification involved three steps.
Table 2. Raw data format of vehicular record for analysis

\begin{tabular}{|c|c|c|c|c|}
\hline Field & Columns & Width & Description & $\begin{array}{c}\text { Variable } \\
\text { used } \\
(\mathrm{VB})\end{array}$ \\
\hline 1 & $1 \ldots 2$ & 2 & MO (month) & $\mathrm{MO}$ \\
\hline 2 & $4 \ldots 5$ & 2 & DA (day) & DA \\
\hline 3 & $7 \ldots 8$ & 2 & YE (year) & $\mathrm{YE}$ \\
\hline 4 & $10 \ldots 11$ & 2 & HO (hour) & $\mathrm{HO}$ \\
\hline 5 & $13 \ldots 14$ & 2 & MI (minute) & MI \\
\hline 6 & $16 \ldots 17$ & 2 & SE (second) & SE \\
\hline 7 & $28 \ldots 29$ & 2 & LN (lane) & LN \\
\hline 8 & $60 \ldots 63$ & 4 & SPEE (speed $[\mathrm{km} / \mathrm{h}])$ & SPD \\
\hline 9 & $65 \ldots 70$ & 6 & LENG (length $[\mathrm{cm}]$ ) & LEN \\
\hline 10 & $72 \ldots 75$ & 4 & ESAL & ESAL \\
\hline 11 & $77 \ldots 80$ & 4 & TODT (wheelbase $[\mathrm{cm}]$ ) & $\mathrm{TD}$ \\
\hline 12 & $82 \ldots 85$ & 4 & $\begin{array}{l}\text { TWT3 (total weight } \\
[\mathrm{kg} \times 100])\end{array}$ & TW \\
\hline 13 & $87 \ldots 90$ & 4 & $\begin{array}{l}\text { DTB1 (front to axle } \\
1[\mathrm{~cm}])\end{array}$ & D01 \\
\hline 14 & $92 \ldots 95$ & 4 & $\begin{array}{l}\text { WT13 (axle weight } \\
1[\mathrm{~kg} \times 100])\end{array}$ & W1 \\
\hline 15 & $97 \ldots 100$ & 4 & $\begin{array}{l}\text { DT12 (axle spacing } \\
12[\mathrm{~cm}])\end{array}$ & D12 \\
\hline 16 & $102 \ldots 105$ & 4 & $\begin{array}{l}\text { WT23 (axle weight } \\
2[\mathrm{~kg} \times 100])\end{array}$ & W2 \\
\hline 17 & $107 \ldots 110$ & 4 & $\begin{array}{l}\text { DT23 (axle spacing } \\
23[\mathrm{~cm}])\end{array}$ & D23 \\
\hline 18 & $112 \ldots 115$ & 4 & $\begin{array}{l}\text { WT33 (axle weight } \\
3[\mathrm{~kg} \times 100])\end{array}$ & W3 \\
\hline 19 & $117 \ldots 120$ & 4 & $\begin{array}{l}\text { DT34 (axle spacing } \\
34[\mathrm{~cm}])\end{array}$ & D34 \\
\hline 20 & $122 \ldots 125$ & 4 & $\begin{array}{l}\text { WT43 (axle weight } \\
4[\mathrm{~kg} \times 100])\end{array}$ & W4 \\
\hline 21 & $127 \ldots 130$ & 4 & $\begin{array}{l}\text { DT45 (axle spacing } \\
45[\mathrm{~cm}])\end{array}$ & D45 \\
\hline 22 & $132 \ldots 135$ & 4 & $\begin{array}{l}\text { WT53 (axle weight } \\
5[\mathrm{~kg} \times 100])\end{array}$ & W5 \\
\hline 23 & $137 \ldots 140$ & 4 & $\begin{array}{l}\text { DT56 } \\
\text { (axle spacing } 56[\mathrm{~cm}])\end{array}$ & D56 \\
\hline 24 & $142 \ldots 145$ & 4 & $\begin{array}{l}\text { WT63 (axle weight } \\
6[\mathrm{~kg} \times 100])\end{array}$ & W6 \\
\hline 25 & $147 \ldots 150$ & 4 & $\begin{array}{l}\text { DT67 (axle spacing } \\
67[\mathrm{~cm}])\end{array}$ & D67 \\
\hline 26 & $152 \ldots 155$ & 4 & $\begin{array}{l}\text { WT73 (axle weight } \\
7[\mathrm{~kg} \times 100])\end{array}$ & W7 \\
\hline 27 & $157 \ldots 160$ & 4 & $\begin{array}{l}\text { DT78 (axle spacing } \\
78[\mathrm{~cm}])\end{array}$ & D78 \\
\hline 28 & $162 \ldots 165$ & 4 & $\begin{array}{l}\text { WT83 (axle weight } \\
8[\mathrm{~kg} \times 100])\end{array}$ & W8 \\
\hline 29 & $167 \ldots 170$ & 4 & $\begin{array}{l}\text { DT89 (axle spacing } \\
89[\mathrm{~cm}])\end{array}$ & D89 \\
\hline 30 & $172 \ldots 175$ & 4 & $\begin{array}{l}\text { WT93 (axle weight } \\
9[\mathrm{~kg} \times 100])\end{array}$ & W9 \\
\hline
\end{tabular}




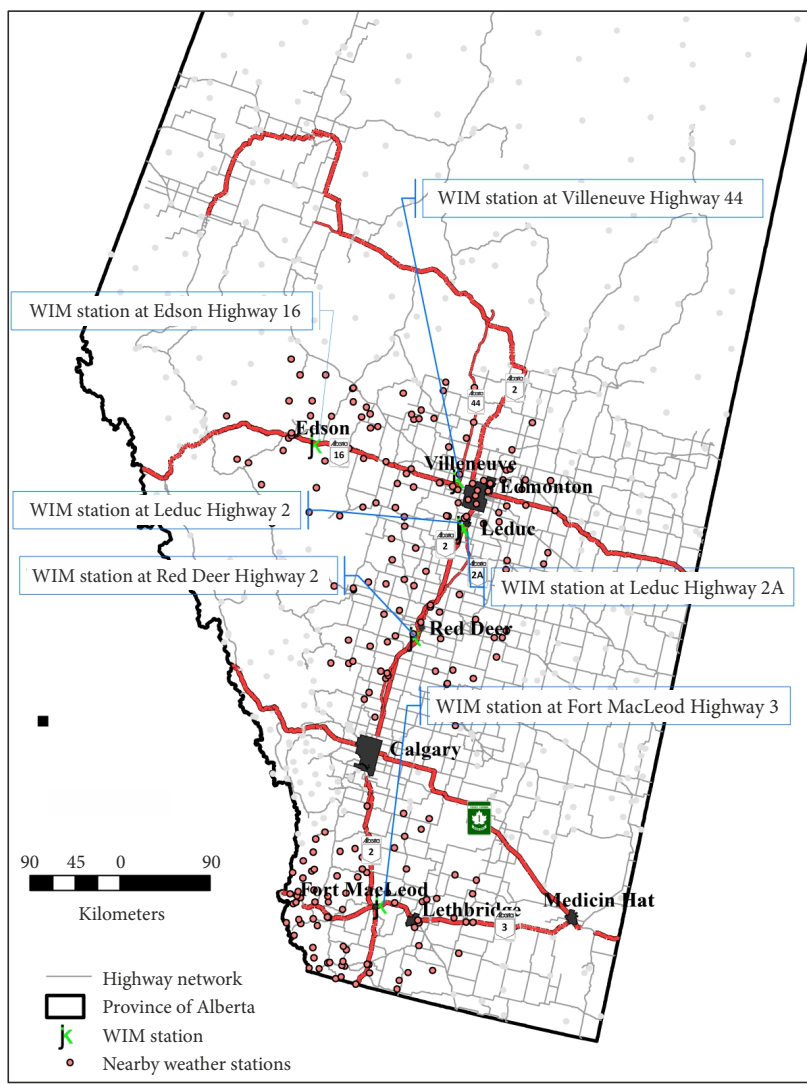

Figure 1. Thematic map showing cities in Alberta, study WIM sites, nearby weather stations, and highway network

a)

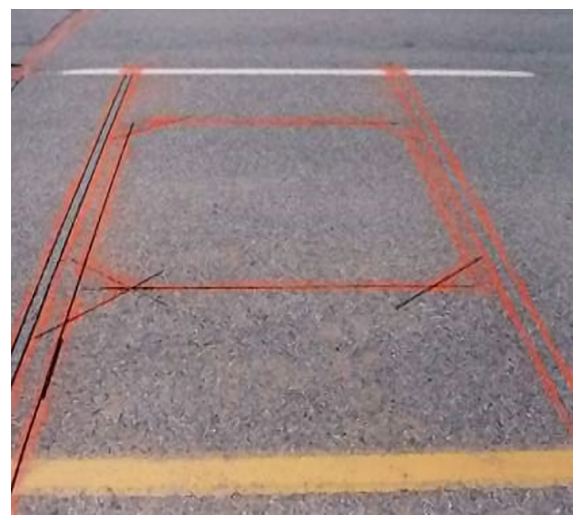

b)

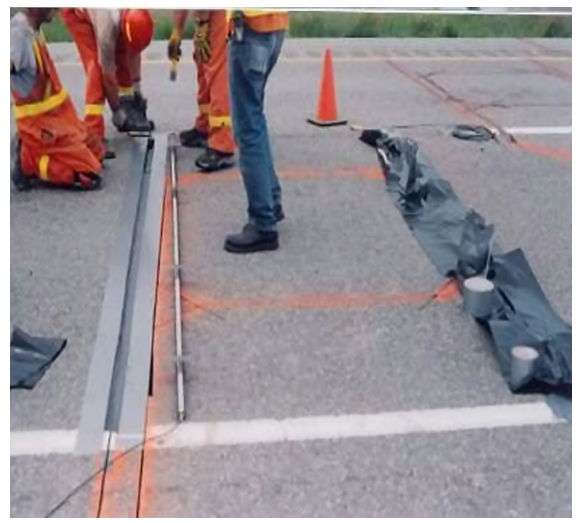

Figure 2. Installation diagrams and photos in Highway 3 site: $\mathrm{a}$ - loop and piezoelectric sensor slot cut; $\mathrm{b}$ - piezoelectric sensor installation
In the first step, some records of the data that have no information on axle spacing were detected and these records were separated from normal records for treatment with additional attention during the course of vehicle classification. For this purpose, initial classification is conducted in order to sort out entire vehicular records into two groups: Reasonable Data Records (RDR) group, and Unreasonable Data Records (UDR) group. The RDR group can proceed further to next classification step, whereas UDR group is not appropriate for classification due to insufficient information of vehicle configuration. For the sake of simple presentation, the details of data compositions of both RDR and UDR group for 5 years study period are tabulated in Table 3 using the Red Deer site located on Highway 2.

Table 3. Data composition in both RDR and UDR groups for Red Deer WIM station

\begin{tabular}{|c|c|c|c|c|}
\hline Year & AADT & $\begin{array}{c}\text { Total data } \\
\text { records }\end{array}$ & $\mathrm{RDR}$ & UDR \\
\hline 2005 & 30480 & 11125215 & 10842124 & 283091 \\
\hline 2006 & 29780 & 10869702 & 10762928 & 106774 \\
\hline 2007 & 33365 & 12178089 & 12063148 & 114941 \\
\hline 2008 & 31165 & 11406341 & 11072873 & 333468 \\
\hline 2009 & 31509 & 11500838 & 11266678 & 234160 \\
\hline \multicolumn{2}{|c|}{ Total } & 57080185 & 56007751 & 1072434 \\
\hline
\end{tabular}

The next step involved the task of sorting the RDR and UDR into daily traffic volumes on which all statistical analyses were carried out. The numbers of vehicular records classified into 13 vehicle classes for each year are summarized in third column from the left in Table 4 . The total number of vehicular records classified for 5 years is in the last row as well. For example, the number (10783397) represents total vehicular records classified into bins of 13 vehicle classes from the RDR dataset through the first classification for the year of 2005.

The FHWA scheme $\mathrm{F}$ has been recognized as a representative vehicle classification algorithm. However, it has also readily been acknowledged through experiences in transportation practices that it has some vagueness in defining axle spacing demarcations (Mussa et al. 2006). To overcome this weakness, another vehicle classification scheme that employs the concept of Probabilistic Neural Network (PNN) as a classification algorithm is applied in this research. In the last step, the PNN classification algorithm is applied to the vehicular records left unclassified through the first classification process. The primary reason to conduct the second round classification is to make sure that significant amount of data is prepared and then plugged into non-parametric statistical analysis.

The key concept of the PNN method, without any mathematical terms, is presented here since the application of PNN is not the main objective of this research. An informative input vector consisting of vehicle configurations such as axle spacing and axle numbers is provided for algebraic calculations with the association with five training samples produced for each of 13 vehicle classes. Based 
on the statistically evaluated value provided through an algebraic calculation, a vehicle-by-vehicle record is classified into 13 classification bins. The PNN algorithm is applied to the vehicular records remained unclassified after completing the first round of classification. In Table 4, the number (58727) means vehicular records left unclassified for the year of 2005. These records were used for further classification with PNN algorithms and classified into 13 vehicle classes, consequently 55180 records were classified and 3547 were finally left unclassified. For non-parametric analysis, 3547 vehicular records left unclassified is considered as truck traffic and 283091 vehicular records seen in UDR group in Table 3 is distributed to each vehicle classes such as passenger cars and truck types in proportion to the ratio of each vehicle classes to total daily traffic. The other remaining five WIM sites are also classified with the same classification procedures used for Red Deer site. The classification procedure is carried out by computer codes developed using Visual Basic Application (VBA) provided in Microsoft Excel.

It should be noted that sample data could not generate sufficient samples to carry out detailed statistical analyses by each vehicle class. This is mainly due to lower number of total trucks ranged in general from 8 to $32 \%$ of total traffic volume for the all six WIM sites. Therefore, the 13 vehicle classes were further aggregated into four major categories such as passenger cars and three truck type classes, namely straight unit trucks, single trailer and multi trailer units.

\section{Impact of weather on truck type distribution in mixed traffic stream}

The province of Alberta experiences severe snowfall and cold conditions from November to March. Winter weather condition of Red Deer WIM site on Highway 2 is presented in Figure 3 with weather data (i.e. temperature and snowfall) obtained from the Environment Canada (Canada.ca 2010) climate database. In Figure 3, the first number (50101) displayed in the $X$-axis means the day of January first of the year 2005. The same naming convention is applied for other dates displayed in the $X$-axis. Based on these observations, the months of November to March, which represents severe snowfall and cold conditions are grouped into two winter month groups (i.e. 5WMs and $3 \mathrm{WMs}$ ) and the remaining months are grouped into nonwinter months (7NWMs).

\subsection{Month to month variations}

To examine whether or not truck type distribution is associated with the month, the truck traffics are separated from the total traffic. With the classification method explained earlier, the truck traffics are categorized into three truck types (i.e. straight unit trucks, single trailer, and multi trailer). Daily average truck volumes according to three truck types are distributed with the 12 months of the year. Normality in the data sets is tested to decide whether or not non-parametric method is appropriate for this study. The test involves composing 90 data sets ( 5 years of data sets for each of six WIM sites arranged for each of three truck types) and computing the normality of each data sets with Anderson-Darling test module available in $R$ statistical computing software (RFSC 2010). 85 data sets out of 90 are found there is more possibility the sample comes from a normal distribution. This normality test results showed that all study data did not always obey the normal distribution, which made the application of parametric tests inappropriate for this study. Therefore, alternative methods for which validity does not depend on rigid assumptions were considered. The non-parametric test procedures met the needs of this study, since they are valid under very general assumptions and no normality is required (Daniel 1990). Therefore, it is valid that combined chi-squared and Binomial test is applicable for those data sets. Combined non-parametric chi-squared and binomial statistical test is then applied to examine the variations of truck type distribution pattern by month.

The chi-squared test is one type of goodness-of-fit test that has been widely applied to compare the observed frequency of event with the expected frequency of event (Daniel 1990). The test statistic results from a comparison of expected and observed frequency patterns. In this study, the daily truck type distribution patterns averaged for each month during the year is considered as one empirical frequency distribution. The other empirical frequency distribution i.e., the expected truck type distribution patterns, is calculated based on the null hypothesis $H_{0}$ : truck type distribution is not associated with the month.

Table 4. Classification results obtained from both FHWA scheme F and PNN classification schemes

\begin{tabular}{|c|c|c|c|c|c|}
\hline \multirow{2}{*}{ Year } & \multirow{2}{*}{ AADT } & First classification using FHWA scheme F & \multicolumn{3}{|c|}{ RDR } \\
\cline { 3 - 6 } & & Classified & Unclassified & Classified cond classification using PNN & Unclassified \\
\cline { 3 - 6 } & 30480 & 10783397 & 58727 & 55180 & 3547 \\
\hline 2005 & 29780 & 10738564 & 24364 & 22964 & 1400 \\
\hline 2006 & 33365 & 12034778 & 28370 & 25911 & 2459 \\
\hline 2007 & 31165 & 11026477 & 46396 & 42408 & 3988 \\
\hline 2008 & 31509 & 11234461 & 32217 & 28206 & 4011 \\
\hline 2009 & & 55817677 & 190074 & 174669 & 15405 \\
\hline \multicolumn{2}{|c|}{ Total } & & & & \\
\hline
\end{tabular}




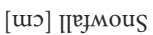

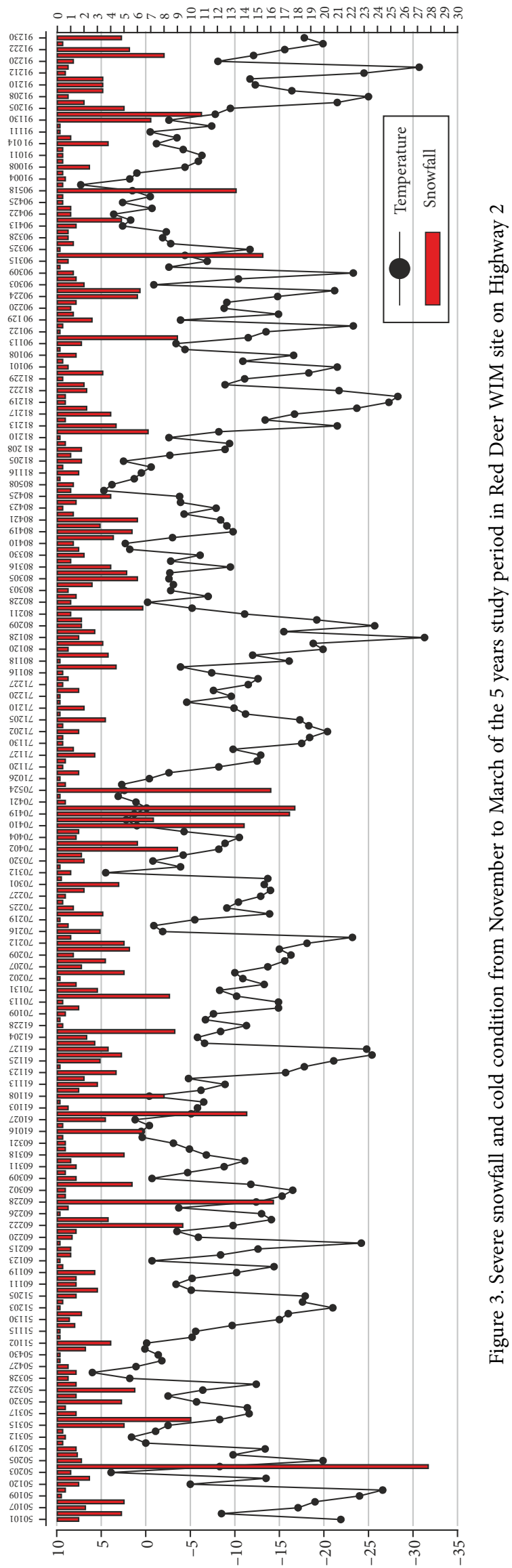

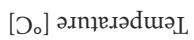


If the two truck type distribution patterns are similar to each other, a close agreement is expected between the observed and expected frequencies with the chi-squared test value smaller than the critical value of chi-squared distribution at significance level $\alpha$. It can be said that the association of truck type distribution with month is not significant.

The chi-squared test examines whether or not truck type distribution is associated with the month of the year for only one individual year, so one year statistical experiment is not enough to reach valid conclusion. In order to establish overall confident decision for the 5 years historical study data, the concept of the Binomial test is additionally applied. In this test, the yearly chi-squared test result over 5 years is considered to obey the binomial probability distribution with the probability of success $(p=0.5)$ on a yearly trial, the number of trial $(n=5)$ being the number of study years in this study. It could be tested whether or not truck type distribution is associated with month for the study period at a $95 \%$ confidence level $(\alpha=0.05)$ with other parameters ( $p=0.5, n=5)$ using the binomial test.

To provide a better understanding of the methodology adopted in this study, a sample analysis is presented in this section. The truck traffic data from Red Deer combined with Leduc study site on Highway 2 for the year 2005 is used for this presentation purpose. Table 5 shows the observed average daily truck type distribution patterns for each month. In order to carry out the chi-squared statistical test, the expected truck type distribution patterns are required as shown in Table 6. The expected truck type distribution patterns are calculated based on the null hypothesis $H_{0}$ : truck type distribution is not associated with the month. The expected truck type distribution can be calculated using Equation (1):

$$
E_{i j}=\left(\frac{n_{i}}{n}\right) \cdot n_{j},
$$

where: $n_{i}, n_{j}$ are marginal grand total for row $i$, the num- ber of truck types and column $j$, the number of months, and $n$ represents a grand total from in Table 5 .

Relationships between observed and expected truck type distribution patterns for the sample study site is graphically described for the 5 years study period in Figure 4. Based on the truck traffic volumes given both in Tables 5 and 6, chi-squared test is conducted. The chisquared test statistic $\left(\chi^{2}=77.40\right)$ is calculated using Equation (2):

$$
\chi^{2}=\sum_{i=1}^{r} \sum_{j=1}^{c}\left(\frac{\left(O_{i j}-E_{i j}\right)^{2}}{E_{i j}}\right) .
$$

From the chi-squared distribution chart in Figure 5, the critical value of chi-squared test corresponding to the given degrees of freedom $d f=(i-1) \cdot(j-1)=22$ and significance level $(\alpha=0.05)$ is 34.92 . The test statistic 77.40 appears greater than the critical value of 34.92 , which is fallen in a rejection region. It can be said that the association of truck type distribution with month is significant for the year 2005. Similar statistical experiments are carried out for the remaining four years from 2006 to 2009 and the results of statistical significant are summarized in Table 7.

It is seen that null hypothesis $H_{0}$ is rejected for the all 5 years of experimental trial. According to the Binomial cumulative probability distribution with parameters like $n=5$ and $p=0.5$ as depicted in Figure 6, the critical value of success $Y$ is 4 out of 5 trials to satisfactorily reject the null hypothesis at the $95 \%$ confidence level. In the example, 5 successes were observed out of 5 trials, meaning null hypothesis is rejected successfully. With chisquared test combined with binomial test, it is statistically significance to say that truck type distribution is associated with the month for the sample site on Highway 2 for 5 years study period.

\begin{tabular}{|c|c|c|c|c|c|c|c|c|c|c|c|c|}
\hline $\begin{array}{l}\text { Observed } \\
\qquad\left(O_{i j}\right)\end{array}$ & $\begin{array}{l}\widehat{\vec{\Xi}} \\
\text { 芯 }\end{array}$ & 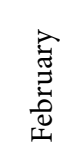 & 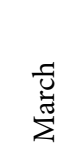 & 蒙 & 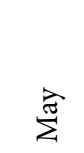 & 五 & 촐 & 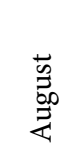 & 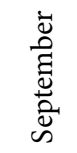 & 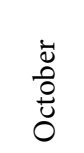 & $\begin{array}{l}\bar{\nu} \\
\vec{\Xi} \\
\stackrel{\nu}{Z} \\
\text { z̆ }\end{array}$ & 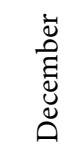 \\
\hline Straight unit & 1056 & 1106 & 1188 & 1287 & 1411 & 1471 & 1544 & 1484 & 1414 & 1389 & 1393 & 1243 \\
\hline Single trailer & 1567 & 1678 & 1712 & 1724 & 1805 & 1863 & 1782 & 1903 & 1967 & 1993 & 2026 & 1769 \\
\hline Multi trailer & 727 & 803 & 923 & 942 & 1023 & 977 & 912 & 966 & 965 & 959 & 991 & 845 \\
\hline
\end{tabular}

Table 5. Observed monthly averaged daily truck type distribution on combined Red Deer and Leduc Vis sites on Highway 2 for 2005

\begin{tabular}{|c|c|c|c|c|c|c|c|c|c|c|c|c|}
\hline $\begin{array}{l}\text { Expected } \\
\left(E_{i j}\right)\end{array}$ & 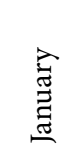 & 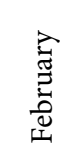 & 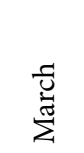 & 宽 & $\stackrel{\text { बे }}{\Sigma^{2}}$ & 吾 & 흐 & $\begin{array}{l}\vec{\omega} \\
0 \\
E_{0} \\
\vec{z}\end{array}$ & 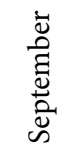 & $\begin{array}{l}\vec{\Delta} \\
\stackrel{0}{0} \\
\vec{U}\end{array}$ & $\begin{array}{l}\vec{\Delta} \\
\vec{\Xi} \\
\text { ठे } \\
\text { z }\end{array}$ & 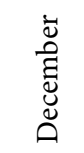 \\
\hline Straight unit & 1097 & 1175 & 1252 & 1295 & 1388 & 1412 & 1388 & 1425 & 1423 & 1422 & 1445 & 1263 \\
\hline Single trailer & 1496 & 1602 & 1707 & 1765 & 1892 & 1924 & 1892 & 1943 & 1940 & 1938 & 1969 & 1722 \\
\hline Multi trailer & 757 & 811 & 864 & 894 & 958 & 974 & 958 & 984 & 982 & 981 & 997 & 872 \\
\hline
\end{tabular}

Table 6. Expected monthly averaged daily truck type distribution on combined Red Deer and Leduc Vis sites on Highway 2 for 2005 
a) Trcuk type distribution for 2005

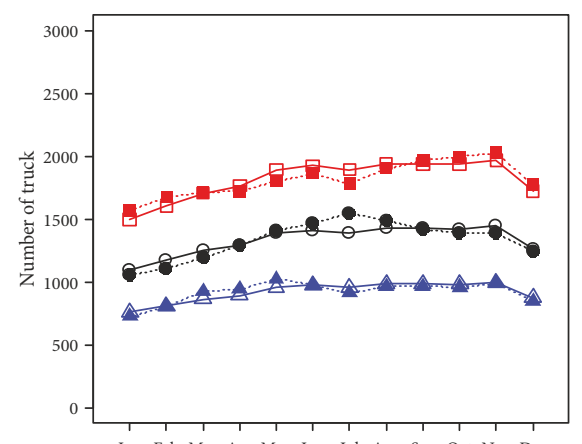

Jan Feb Mar Apr May Jun Jul Aug Sep Oct Nov Dec

d) Trcuk type distribution for 2008

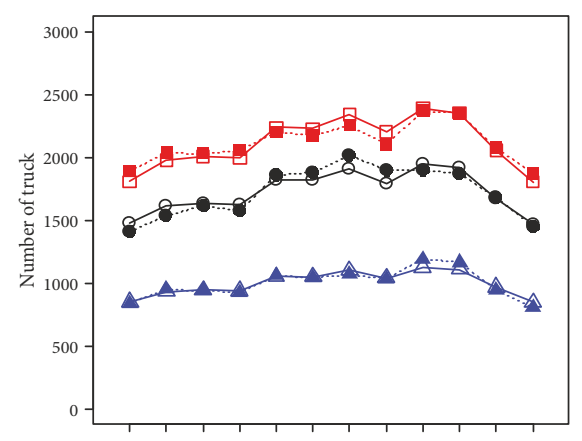

Jan Feb Mar Apr May Jun Jul Aug Sep Oct Nov Dec b) Trcuk type distribution for 2006

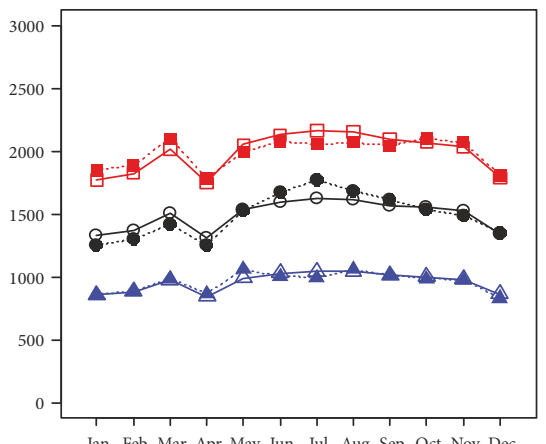

e) Trcuk type distribution for 2009

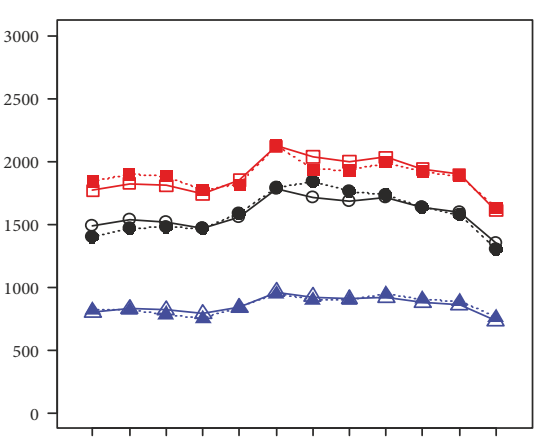

c) Trcuk type distribution for 2007

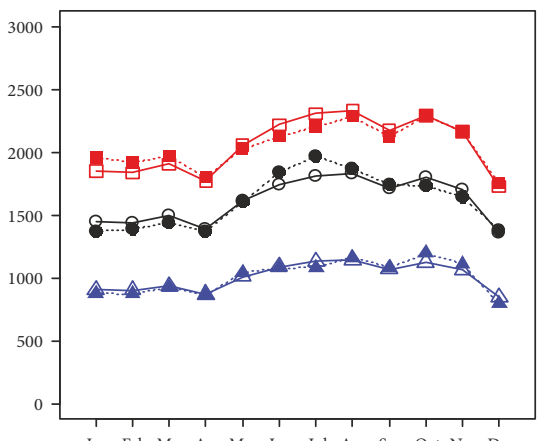

Jan Feb Mar Apr May Jun Jul Aug Sep Oct Nov Dec

Figure 4. Observed and expected truck type distribution patterns in Red Deer site on Highway 2 for 5 years study period

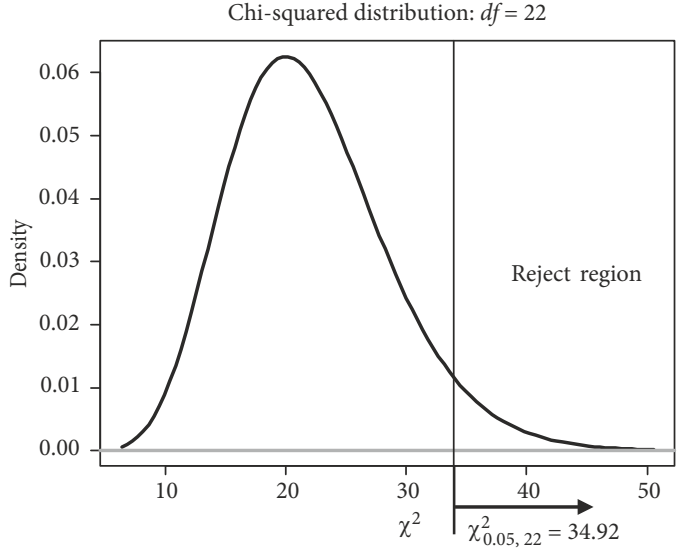

Figure 5. Chi-squared probability distribution

Table 7. Summary of chi-squared test results for month-tomonth truck type distribution on combined Red Deer and Leduc Vis sites on Highway 2 for the 5 years study period

\begin{tabular}{|c|c|c|}
\hline Year & $\chi^{2}(p$-value $)$ & Significance \\
\hline 2005 & $77.40(0.0000)$ & $Y$ (dependent), $H_{1}$ \\
\hline 2006 & $74.00(0.0000)$ & $Y$ (dependent), $H_{1}$ \\
\hline 2007 & $75.10(0.0000)$ & $Y$ (dependent $), H_{1}$ \\
\hline 2008 & $59.35(0.0000)$ & $Y$ (dependent), $H_{1}$ \\
\hline 2009 & $54.56(0.0001)$ & $Y$ (dependent), $H_{1}$ \\
\hline \multicolumn{2}{|c|}{ Number of significant years } & 5 \\
\hline
\end{tabular}

Note: $Y$ - dependent, truck type distribution is associated with month.

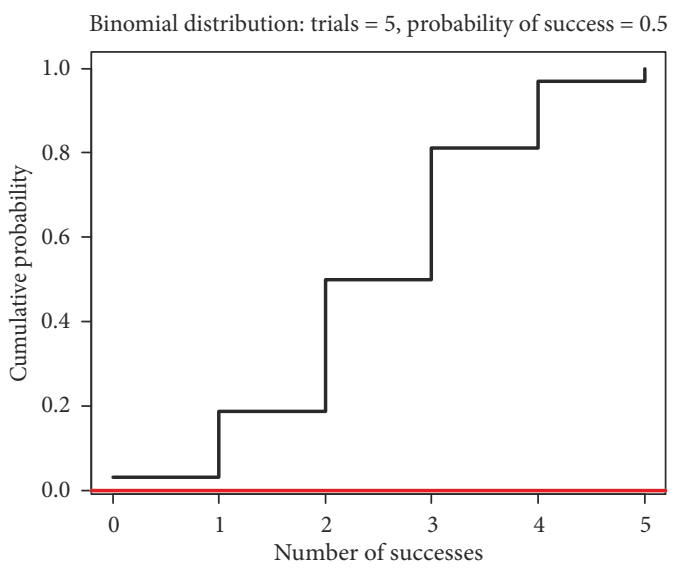

Figure 6. Cumulative binomial distribution

The methodology applied to the sample site on Highway 2 is also applied to other remaining WIM sites to check whether or not truck type distribution is associated with months. The chi-squared statistical test results with $p$-value in parenthesis for the remaining highways WIM sites for the 5 years study period are presented in Table 8 . Binomial test results with $p$-value obtained from the 5 years chi-squared test is summarized in Table 9. The same statistical reasoning process applied in the previous example can be applied to analysis results presented in Tables 8 and 9 . 
Table 8. Summary of chi-squared test results on other WIM sites on highway networks for the 5 years study period

\begin{tabular}{|c|c|c|c|}
\hline Highway & Year & $\chi^{2}(p$-value $)$ & Significance \\
\hline \multirow{6}{*}{$\begin{array}{l}\text { Highway } \\
2 \mathrm{~A}\end{array}$} & 2005 & $241.23(0.0000)$ & $Y$ (dependent), $H_{1}$ \\
\hline & 2006 & $21.02(0.5190)$ & $N$ (independent), $H_{0}$ \\
\hline & 2007 & $62.16(0.0000)$ & $Y$ (dependent), $H_{1}$ \\
\hline & 2008 & $67.81(0.0000)$ & $Y$ (dependent), $H_{1}$ \\
\hline & 2009 & $17.36(0.7430)$ & $N$ (independent), $H_{0}$ \\
\hline & \multicolumn{3}{|c|}{ Number of significant years: 3} \\
\hline \multirow{6}{*}{$\begin{array}{l}\text { Highway } \\
2 \text { - Red } \\
\text { Deer }\end{array}$} & 2005 & $83.65(0.0000)$ & $Y$ (dependent), $H_{1}$ \\
\hline & 2006 & $92.87(0.0000)$ & $Y$ (dependent), $H_{1}$ \\
\hline & 2007 & $100.52(0.0000)$ & $Y$ (dependent), $H_{1}$ \\
\hline & 2008 & $46.58(0.0017)$ & $Y$ (dependent), $H_{1}$ \\
\hline & 2009 & $61.75(0.0000)$ & $Y$ (dependent), $H_{1}$ \\
\hline & \multicolumn{3}{|c|}{ Number of significant years: 5} \\
\hline \multirow{6}{*}{$\begin{array}{l}\text { Highway } \\
3\end{array}$} & 2005 & $259.21(0.0000)$ & $Y$ (dependent), $H_{1}$ \\
\hline & 2006 & $37.42(0.0213)$ & $Y$ (dependent), $H_{1}$ \\
\hline & 2007 & $39.39(0.0127)$ & $Y$ (dependent), $H_{1}$ \\
\hline & 2008 & $42.25(0.0058)$ & $Y$ (dependent), $H_{1}$ \\
\hline & 2009 & $26.06(0.2492)$ & $N$ (independent), $H_{0}$ \\
\hline & \multicolumn{3}{|c|}{ Number of significant years: 4} \\
\hline \multirow{6}{*}{$\begin{array}{l}\text { Highway } \\
16\end{array}$} & 2005 & $210.18(0.0000)$ & $Y$ (dependent), $H_{1}$ \\
\hline & 2006 & $53.21(0.0002)$ & $Y$ (dependent), $H_{1}$ \\
\hline & 2007 & $66.39(0.0000)$ & $Y$ (dependent), $H_{1}$ \\
\hline & 2008 & $42.64(0.0052)$ & $Y$ (dependent), $H_{1}$ \\
\hline & 2009 & $42.21(0.0059)$ & $Y$ (dependent), $H_{1}$ \\
\hline & \multicolumn{3}{|c|}{ Number of significant years: 5} \\
\hline \multirow{6}{*}{$\begin{array}{l}\text { Highway } \\
44\end{array}$} & 2005 & $769.35(0.0000)$ & $Y$ (dependent), $H_{1}$ \\
\hline & 2006 & $183.66(0.0000)$ & $Y$ (dependent), $H_{1}$ \\
\hline & 2007 & $448.04(0.0000)$ & $Y$ (dependent), $H_{1}$ \\
\hline & 2008 & $212.84(0.0000)$ & $Y$ (dependent), $H_{1}$ \\
\hline & 2009 & $180.08(0.0000)$ & $Y$ (dependent), $H_{1}$ \\
\hline & \multicolumn{3}{|c|}{ Number of significant years: 5} \\
\hline
\end{tabular}

Table 9. Summary of binomial test results on other WIM sites on highway networks

\begin{tabular}{|l|c|c|}
\hline \multicolumn{1}{|c|}{ Highway } & $\begin{array}{c}\text { Binomial } \\
(p \text {-value })\end{array}$ & Significance \\
\hline Highway 2A & $3(0.188)$ & $N$ (independent), $H_{0}$ \\
\hline Highway 2 - Red Deer & $5(0.000)$ & $Y$ (dependent), $H_{1}$ \\
\hline Highway 3 & $4(0.031)$ & $Y$ (dependent), $H_{1}$ \\
\hline Highway 16 & $5(0.000)$ & $Y$ (dependent), $H_{1}$ \\
\hline Highway 44 & $5(0.000)$ & $Y$ (dependent), $H_{1}$ \\
\hline
\end{tabular}

\subsection{Season to season variations}

This section investigates on whether or not truck type distribution is associated with seasons. As a calculation example, the seasonal association of truck type distribution with winter months (or non-winter month) for Highway $2 \mathrm{~A}$ is presented in this section.

It has long been recognized that weather condition is a factor affecting highway traffic flow especially for regions in North America where inclement weather conditions continues during winter season. Owing to the geographical location, the winter weather in Canada is very severe with extremely cold temperatures (below $-35^{\circ} \mathrm{C}$ ), heavy snowfall, blizzards, freezing rain and high wind chills. Such weather conditions may result in significant variations in highway traffic patterns. To understand the truck type distribution patterns during winter months as compared to non-winter month (or summer months), the months of November to March that experience lots of amount of snowfall and severe cold temperature are grouped into two temporal winter month groups (3WMs, $5 \mathrm{WMs}$ ) as noted in introduction section and the remaining months are grouped into non-winter months (7NWNs).

Using the same methodology utilized in the previous section, the monthly average daily truck type distribution patterns observed from truck traffic events and their expected values are calculated for winter month and nonwinter month groups for the Highway 2A including other study sites for the years from 2005 to 2009. As an example, the observed and expected truck traffic distribution patterns with respect to $5 \mathrm{WMs}$ and $7 \mathrm{NWMs}$ for the year 2005 are summarized in Table 10.

The chi-squared test statistic for the Highway 2A site for the year 2005 is estimated using Equation (2) and found to be 8.37. The critical value of $\chi^{2}$ for 2 degrees of freedom at $95 \%$ confidence level is turned out to be 5.99. Since the test value 8.37 is greater than 5.99 , falling in rejection region, it can statistically be said that the truck type distribution differs from season to season in particular for the year 2005 for Highway 2A site. The same analysis is repeatedly carried out for the remaining four years from 2006 to 2009 and the results are summarized in Table 11.

Table 10. Observed and expected seasonal truck type distributions for 5WMs vs. 7NWMs on Highway 2A site for year 2005

\begin{tabular}{|l|c|c|l|c|c|}
\hline $\begin{array}{c}\text { Observed } \\
\left(O_{i j}\right)\end{array}$ & $5 \mathrm{WMs}$ & $7 \mathrm{NWMs}$ & $\begin{array}{l}\text { Expected } \\
\left(E_{i j}\right)\end{array}$ & $5 \mathrm{WMs}$ & $7 \mathrm{NWMs}$ \\
\hline $\begin{array}{l}\text { Straight } \\
\text { unit }\end{array}$ & 269 & 305 & $\begin{array}{l}\text { Straight } \\
\text { unit }\end{array}$ & 262 & 312 \\
\hline $\begin{array}{l}\text { Single } \\
\text { trailer }\end{array}$ & 131 & 139 & $\begin{array}{l}\text { Single } \\
\text { trailer }\end{array}$ & 123 & 147 \\
\hline $\begin{array}{l}\text { Multi } \\
\text { trailer }\end{array}$ & 42 & 83 & $\begin{array}{l}\text { Multi } \\
\text { trailer }\end{array}$ & 57 & 68 \\
\hline
\end{tabular}

Table 11. Summary of chi-squared test results for two temporal winter month groups (5WMs vs. 7NWMs) for Highway $2 \mathrm{~A}$ site for 5 years study period

\begin{tabular}{|c|c|c|}
\hline Year & $\chi^{2}(p$-value $)$ & Significance \\
\hline 2005 & $8.71(0.013)$ & $Y$ (dependent), $H_{1}$ \\
\hline 2006 & $0.44(0.801)$ & $N$ (independent), $H_{0}$ \\
\hline 2007 & $5.50(0.064)$ & $N$ (independent), $H_{0}$ \\
\hline 2008 & $3.55(0.169)$ & $N$ (independent), $H_{0}$ \\
\hline 2009 & $0.52(0.771)$ & $N$ (independent), $H_{0}$ \\
\hline \multicolumn{3}{|c|}{ Number of significant years: 1} \\
\hline
\end{tabular}


Subsequently, Binomial test is applied to determine overall significance of the site for entire historical data by combining yearly result of chi-squared test conducted over 5 years study period. According to Figure 6 presenting cumulative binomial distribution, for the sample size of 5 and success probability of 0.5 , the critical value of the binomial test is 4 to reject the null hypothesis $H_{0}$, satisfying the $95 \%$ confidence level. The only one single experiment conducted for the year 2005 appears significant out of five trials, thereby not rejecting null hypothesis. In other words, there is insufficient evidence to reject the null hypothesis. Consequently, with the help of combined chi-squared and binomial test results, it can statistically be appropriate to say that the truck type distribution is not associated with the season for the Highway $2 \mathrm{~A}$ site.

Similar methodology is applied for all WIM sites with respect to two pairs of winter month combination groups (3WMs vs. 7NWMs and 5WMs vs. 7NWMs). After completing 5 years repeated chi-squared test, the summary of chi-squared test value with $p$-value in parenthesis for all WIM sites is presented in Table 12. In the same line of statistical reasoning applied to the sample Highway $2 \mathrm{~A}$ site, the binomial test are conducted at $95 \%$ confidence level and the test results with $p$-value are tabulated in the Table 13.

It is observed from Table 13 that the Highway 2A, which is a dominantly commuter type road in terms of travel characteristic of travel populations is maintaining stable truck traffic volume distribution in terms of truck types irrespective of two pairs of winter month combination groups at $95 \%$ confidence level. The truck traffic on Highway 3 and Highway 16, which fall in a regional long distance type road are also not affected in truck type distribution by seasonal combination groups similar to Highway 2A. In case of Highway 2, which is a regional long distance road, the truck traffic is in stable distribution across season between winter and non-winter period at the same confidence level. The Highway 44, which is classified into a special type road differentiating itself from other sites indicated that season is an important factor affecting truck traffic distributions with significant statistical evidence.

One consistent conclusion drawn from the Highway 2A site having dominantly commuter traffics is that the truck type distribution is not affected between months, and even between seasons. Similarly, truck type distribution pattern is affected by monthly, but not affected by two pairs of seasonal group for Highway 2, Highway 3 and Highway 16, which belongs to regional long distance road. These findings provide useful insights for highway agencies at initial stage of designing traffic monitoring program. As a practical application, truck traffic counting could be conducted for Highway $2 \mathrm{~A}$ in any time of the year with very flexible counting durations ranging from a few days to several months. In cases for Highways 2, 3, and 16, it is suggested that the short duration truck traffic count can be carried out for periods ranging from a few days to several weeks but less than a month. On highways like Highway 44, the short duration truck traffic count can be carried out either in summer or winter season in order to consider seasonal effect in truck traffic counting.

\section{Conclusions}

The literature clearly indicates that severe weather conditions trigger variations in highway traffic. However, past studies in this area were conducted with overall total traffic flow, not separately considered truck traffic in mixed traffic stream. Understanding of truck traffic variations under severe weather conditions could provide useful information for transportation planning and engineering applications.

This paper developed a non-parametric statistical techniques and they are applied to investigate the impact of months and seasons on the variations of three truck type distribution: straight unit trucks, single trailer, and multi trailer in mixed traffic stream. The investigation is based on five years of six WIM data from Highway 2, Highway 2A, Highway 3, Highway 16 and Highway 44 in Alberta (Canada). Statistical significant of the variations of truck type distributions are investigated to understand the association of their distribution with months and seasons for the 5 years study period by means of combined non-parametric hi-squared and binomial probability test. From the combined statistical test results, the test statistic of $\chi^{2}$ values calculated from the expected and observed truck type distribution patterns for months and seasons are compared with the critical $\chi^{2}$ values at the $95 \%$ confidence level. This procedure is carried out for all the six highway WIM locations considered under this study to understand the association of months (and seasons) with the truck type distribution.

The statistical test results indicated that the truck type distribution is associated with months for all the five WIM sites except for the Highway 2A. In other words, in case of pure commuter road like the Highway 2A, the truck type distribution is not affected by month, meaning that truck type distribution is in overall stable condition throughout the 5 years study period. However, truck type distributions on most rural long distance roads like Highway 2, Highway 3 , Highway 16, and on special road like Highway 44 are associated with months.

Another conclusion that could be drawn from the analyses presented in this paper is that the truck type distribution is not affected due to severe weather condition during winter season for primary highway facilities like Highway 2A, which serve predominantly commuter type of travels. Similarly, the severe winter months in Alberta also do not seem to have significant impact on different truck classes on long distance highways like Highway 2, Highway 3, or Highway 16. On the other hand, highway facility like the Highway 44 serving significant amount of truck seasonal traffic in nature is likely to be affected by seasons of the year. 
Table 12. Summary of chi-squared test results for two pairs of winter month combination groups

(3WMs vs. 7NWMs and 5WMs vs. 7NWMs) for all WIM sites for 5 years study period

\begin{tabular}{|c|c|c|c|c|c|}
\hline \multirow{2}{*}{ Highway } & \multirow{2}{*}{ Year } & \multicolumn{2}{|c|}{3 WMs vs. 7 NWMs comparison } & \multicolumn{2}{|c|}{5 WMs vs. 7 NWMs comparison } \\
\hline & & $\chi^{2}(p$-value $)$ & Significant & $\chi^{2}(p$-value $)$ & Significant \\
\hline \multirow{6}{*}{ Highway 2A } & 2005 & $8.82(0.0122)$ & $Y$ (dependent), $H_{1}$ & $8.71(0.0128)$ & $Y$ (dependent), $H_{1}$ \\
\hline & 2006 & $1.48(0.4776)$ & $N$ (independent), $H_{0}$ & $0.44(0.8013)$ & $N$ (independent), $H_{0}$ \\
\hline & 2007 & $7.81(0.0202)$ & $Y$ (dependent), $H_{1}$ & $5.50(0.0640)$ & $N$ (independent), $H_{0}$ \\
\hline & 2008 & $4.18(0.1238)$ & $N$ (independent), $H_{0}$ & $3.55(0.1691)$ & $N$ (independent), $H_{0}$ \\
\hline & 2009 & $1.31(0.5190)$ & $N$ (independent), $H_{0}$ & $0.52(0.7712)$ & $N$ (independent), $H_{0}$ \\
\hline & \multicolumn{2}{|c|}{ Number of significant years } & 2 & & 1 \\
\hline \multirow{6}{*}{ Highway 2 - Red Deer } & 2005 & $5.54(0.0628)$ & $N$ (independent), $H_{0}$ & $4.30(0.1164)$ & $N$ (independent), $H_{0}$ \\
\hline & 2006 & $4.86(0.0879)$ & $N$ (independent), $H_{0}$ & $5.53(0.0631)$ & $N$ (independent), $H_{0}$ \\
\hline & 2007 & $9.40(0.0091)$ & $Y$ (dependent), $H_{1}$ & $8.13(0.0171)$ & $Y$ (dependent), $H_{1}$ \\
\hline & 2008 & $6.05(0.0485)$ & $Y$ (dependent), $H_{1}$ & $3.27(0.1952)$ & $N$ (independent), $H_{0}$ \\
\hline & 2009 & $7.61(0.0223)$ & $Y$ (dependent), $H_{1}$ & $5.78(0.0555)$ & $N$ (independent), $H_{0}$ \\
\hline & \multicolumn{2}{|c|}{ Number of significant years } & 3 & & 1 \\
\hline \multirow{6}{*}{ Highway 3} & 2005 & $8.13(0.0171)$ & $Y$ (dependent), $H_{1}$ & $0.87(0.6480)$ & $N$ (independent), $H_{0}$ \\
\hline & 2006 & $1.29(0.5245)$ & $N$ (independent), $H_{0}$ & $5.83(0.0541)$ & $N$ (independent), $H_{0}$ \\
\hline & 2007 & $0.25(0.8827)$ & $N$ (independent), $H_{0}$ & $1.40(0.4973)$ & $N$ (independent), $H_{0}$ \\
\hline & 2008 & $0.67(0.7158)$ & $N$ (independent), $H_{0}$ & $0.67(0.7143)$ & $N$ (independent), $H_{0}$ \\
\hline & 2009 & $1.13(0.5681)$ & $N$ (independent), $H_{0}$ & $1.06(0.5900)$ & $N$ (independent), $H_{0}$ \\
\hline & \multicolumn{2}{|c|}{ Number of significant years } & 1 & & 0 \\
\hline \multirow{6}{*}{ Highway 16} & 2005 & $11.46(0.0033)$ & $Y$ (dependent), $H_{1}$ & $8.90(0.0117)$ & $Y$ (dependent), $H_{1}$ \\
\hline & 2006 & $1.81(0.4038)$ & $N$ (independent), $H_{0}$ & $1.76(0.4138)$ & $N$ (independent), $H_{0}$ \\
\hline & 2007 & $2.32(0.3132)$ & $N$ (independent), $H_{0}$ & $3.17(0.2053)$ & $N$ (independent), $H_{0}$ \\
\hline & 2008 & $3.39(0.1840)$ & $N$ (independent), $H_{0}$ & $2.97(0.2270)$ & $N$ (independent), $H_{0}$ \\
\hline & 2009 & $3.11(0.2114)$ & $N$ (independent), $H_{0}$ & $2.38(0.3036)$ & $N$ (independent), $H_{0}$ \\
\hline & \multicolumn{2}{|c|}{ Number of significant years } & 1 & & 1 \\
\hline \multirow{6}{*}{ Highway 44} & 2005 & $48.30(0.0000)$ & $Y$ (dependent), $H_{1}$ & $26.29(0.0000)$ & $Y$ (dependent), $H_{1}$ \\
\hline & 2006 & $23.48(0.0000)$ & $Y$ (dependent), $H_{1}$ & $16.95(0.0002)$ & $Y$ (dependent), $H_{1}$ \\
\hline & 2007 & $73.74(0.0000)$ & $Y$ (dependent), $H_{1}$ & $52.37(0.0000)$ & $Y$ (dependent), $H_{1}$ \\
\hline & 2008 & $27.07(0.0000)$ & $Y$ (dependent), $H_{1}$ & $19.46(0.0000)$ & $Y$ (dependent), $H_{1}$ \\
\hline & 2009 & $9.33(0.0094)$ & $Y$ (dependent), $H_{1}$ & $11.10(0.0039)$ & $Y$ (dependent), $H_{1}$ \\
\hline & \multicolumn{2}{|c|}{ Number of significant years } & 5 & & 5 \\
\hline
\end{tabular}

Table 13. Summary of binomial test results on other WIM sites on highway networks for two pairs of winter month combination groups (3WMs vs. 7NWMs and 5WMs vs. 7NWMs)

\begin{tabular}{|c|c|c|c|c|c|}
\hline Highway & Month & ination & $b-\mathrm{te}$ & ue) & Significance \\
\hline Highway 2A & $\begin{array}{l}3 \mathrm{WMs}^{*} \text { vs. } \\
7 \mathrm{NWMs}^{* * *}\end{array}$ & $\begin{array}{c}5 \mathrm{WMs}^{\star *} \text { vs. } \\
7 \mathrm{NWMs}\end{array}$ & $2(0.5000)$ & $1(0.8130)$ & $N$ (independent), $H_{0}$ \\
\hline Highway 2- Red Deer & $\begin{array}{l}\text { 3WMs vs. } \\
7 \text { NWMs }\end{array}$ & $\begin{array}{l}\text { 5WMs vs. } \\
7 \text { NWMs }\end{array}$ & $3(0.1880)$ & $1(0.8130)$ & $N$ (independent), $H_{0}$ \\
\hline Highway 2 - Leduc Vis & $\begin{array}{l}\text { 3WMs vs. } \\
7 \text { NWMs }\end{array}$ & $\begin{array}{l}\text { 5WMs vs. } \\
7 \text { NWMs }\end{array}$ & $3(0.1880)$ & $1(0.8130)$ & $N$ (independent), $H_{0}$ \\
\hline Highway 2 - Combined & $\begin{array}{l}\text { 3WMs vs. } \\
7 \text { NWMs }\end{array}$ & $\begin{array}{l}\text { 5WMs vs. } \\
7 \text { NWMs }\end{array}$ & $2(0.5000)$ & $0(0.9690)$ & $N$ (independent), $H_{0}$ \\
\hline Highway 3 & $\begin{array}{l}\text { 3WMs vs. } \\
7 \text { NWMs }\end{array}$ & $\begin{array}{l}\text { 5WMs vs. } \\
7 \text { NWMs }\end{array}$ & $1(0.8130)$ & $0(0.9690)$ & $N$ (independent), $H_{0}$ \\
\hline Highway 16 & $\begin{array}{l}\text { 3WMs vs. } \\
7 \text { NWMs }\end{array}$ & $\begin{array}{l}\text { 5WMs vs. } \\
7 \text { NWMs }\end{array}$ & $1(0.8130)$ & $1(0.8130)$ & $N$ (independent), $H_{0}$ \\
\hline Highway 44 & $\begin{array}{l}\text { 3WMs vs. } \\
7 \text { NWMs }\end{array}$ & $\begin{array}{l}\text { 5WMs vs. } \\
7 \text { NWMs }\end{array}$ & $5(0.0000)$ & $5(0.0000)$ & $Y$ (dependent), $H_{1}$ \\
\hline
\end{tabular}

Notes: $3 \mathrm{WMs}^{\star}$ - from December to February; $5 \mathrm{WMs}^{\star \star}$ - from November to March; $7 \mathrm{NWMs} \mathrm{s}^{\star \star *}$ - from April to October. 
The impact analysis of season on truck types is evidently established well with $95 \%$ confidence level for all six highway road segments. These findings have a practical implications for rationalization of schedule and duration of truck traffic counts throughout the year. For example, the short duration truck traffic count for periods ranging from a few days to several weeks but less than a month can be carried out even during winter seasons to get reasonably good estimates of truck traffic on highways like Highway 2A, Highway 2, Highway 3, and Highway 16. Furthermore, the methodology adopted for independency test could contribute in literature for other researchers. The knowledge about independency of truck type distribution to various seasons and month would be useful for many transportation agencies in developing truck traffic counting programs and estimating the highway planning and design parameters like Annual ADTT (AADTT), ADTT and Design Hour Truck Volume (DHTV). Further research on this will able to rationalize the length and frequency of the truck counts for various road types.

\section{References}

Canada.ca. 2010. Canadian Climate Data and Scenarios. Environment Canada, Government of Canada. Available from Internet: http://climate-scenarios.canada.ca/?page=main

Changnon, S. A. 1996. Effects of summer precipitation on urban transportation, Climatic Change 32(4): 481-494. https://doi.org/10.1007/BF00140357

Colyar, J.; Zhang, L.; Halkias, J. 2003. Identifying and assessing key weather-related parameters and their impact on traffic operations using simulation, in Institute of Transportation Engineers 2003 Annual Meeting and Exhibit (Held in Conjunction with ITE District 6 Annual Meeting), 24-27 August 2003, Seattle, Washington, US, 1-23.

Daniel, W. W. 1990. Applied Nonparametric Statistics. Cengage Learning. $656 \mathrm{p}$.

Datla, S.; Sharma, S. 2008. Impact of cold and snow on temporal and spatial variations of highway traffic volumes, Journal of Transport Geography 16(5): 358-372.

https://doi.org/10.1016/j.jtrangeo.2007.12.003

Goodwin, L. C. 2002. Weather Impacts on Arterial Traffic Flow. The Road Weather Management Program, Federal Highway Administration (FHWA), US Department of Transportation, Washington, DC, US. 5 p.

Hanbali, R. M.; Kuemmel, D. A. 1993. Traffic volume reductions due to winter storm conditions, Transportation Research Record: Journal of the Transportation Research Board 1387: 159-164.

Hassan, Y. A.; Barker, D. J. 1999. The impact of unseasonable or extreme weather on traffic activity within Lothian region, Scotland, Journal of Transport Geography 7(3): 209-213. https://doi.org/10.1016/S0966-6923(98)00047-7

Keay, K.; Simmonds, I. 2005. The association of rainfall and other weather variables with road traffic volume in Melbourne, Australia, Accident Analysis \& Prevention 37(1): 109-124. https://doi.org/10.1016/j.aap.2004.07.005

Kilburn, P. 2008. Alberta Infrastructure and Transportation Weigh in Motion Report. Government of Alberta, Ministry of Transportation, Calgary, Canada.
Kilpeläinen, M.; Summala, H. 2007. Effects of weather and weather forecasts on driver behaviour, Transportation Research Part F: Traffic Psychology and Behaviour 10(4): 288299. https://doi.org/10.1016/j.trf.2006.11.002

Knapp, K. K.; Smithson, L. D. 2000. Winter storm event volume impact analysis using multiple-source archived monitoring data, Transportation Research Record: Journal of the Transportation Research Board 1700: 10-16.

https://doi.org/10.3141/1700-03

Liu, Z. 2006. Study of Highway Traffic Peaking Due to Statutory Holidays: PhD Thesis. University of Regina, Saskatchewan, Canada. 246 p.

Maki, P. J. 1999. Adverse weather traffic signal timing, in Transportation Frontiers for the Next Millennium: 69th Annual Meeting of the Institute of Transportation Engineers, 1-4 August 1999, Las Vegas, Nevada, US, 1-8.

Maze, T. H.; Agarwal, M.; Burchett, G. 2006. Whether weather matters to traffic demand, traffic safety, and traffic operations and flow, Transportation Research Record: Journal of the Transportation Research Board 1948: 170-176. https://doi.org/10.1177/0361198106194800119

Mussa, R.; Kwigizile, V.; Selekwa, M. 2006. Probabilistic neural networks application for vehicle classification, Journal of Transportation Engineering 132(4): 293-302. https://doi.org/10.1061/(ASCE)0733-947X(2006)132:4(293)

RFSC. 2010. R: A Language and Environment for Statistical Computing. R Foundation for Statistical Computing (RFSC). 2673 p.

Roh, H.-J.; Datla, S.; Sharma, S. 2012. Impact of winter conditions on truck type distribution on Alberta highways, in 9th International Transportation Specialty Conference (CSCE), 6-9 June 2012, Edmonton, Alberta, Canada.

Roh, H.-J.; Sharma, S.; Sahu, P. K. 2016a. Modeling snow and cold effects for classified highway traffic volumes, KSCE Journal of Civil Engineering 20(4): 1514-1525. https://doi.org/10.1007/s12205-015-0236-0

Roh, H.-J.; Sahu, P. K.; Sharma, S.; Datla, S.; Mehran, B. 2016 b. Statistical investigations of snowfall and temperature interaction with passenger car and truck traffic on primary highways in Canada, Journal of Cold Regions Engineering 30(2). https://doi.org/10.1061/(ASCE)CR.1943-5495.0000099

Roh, H.-J.; Sharma, S.; Sahu, P. K.; Datla, S. 2015. Analysis and modeling of highway truck traffic volume variations during severe winter weather conditions in Canada, Journal of Modern Transportation 23(3): 228-239. https://doi.org/10.1007/s40534-015-0082-2

Wyman, J. H.; Braley, G. A.; Stephens R. I. 1985. Field Evaluation of FHWA Vehicle Classification Categories: Final Report. Publication No DTFH-71-80-54-ME-03. Federal Highway Administration (FHWA), US Department of Transportation, Washington, DC, US. 104 p. Available from Internet: https://rosap.ntl.bts.gov/view/dot/30632 